\title{
Analisis Perubahan Waktu Pengeringan Terhadap Variasi Tinggi Cerobong
}

\author{
Muhammad Syafrun*1, Syukri Himran ${ }^{1}$, Wahyu H. Piarah ${ }^{1}$ \\ ${ }^{1}$ Departemen Teknik Mesin, Fakultas Teknik, Universitas Hasanuddin \\ J1. Poros Malino Km. 6, Bontomarannu, Kabupaten Gowa, Sulawesi Selatan, 92171 \\ *Email : muh_safrun@yahoo.com
}

DOI: 10.25042/jpe.052018.01

\begin{abstract}
Abstrak
Penelitian ini bertujuan untuk mengetahui efisiensi alat pengering gabah dengan menggunakan cerobong dan kipas sebagai pengisap udara dari kolektor ke ruang pengering. Penelitian ini dilakukan di Pusat Laboratorium Jurusan Teknik Mesin Fakultas Teknik Universitas Muslim Indonesia. Metode yang digunakan adalah dengan membuat sebuah alat pengering dengan seng plat 0,2 mm sebagai kolektor dengan menggunakan udara panas dan tenaga matahari sebagai media pengering. Alat ini diharapkan dapat mengeringkan gabah dengan cepat dan tingkat kekeringan (kandungan air) yang merata. Pada penelitian ini dilakukan 5 variasi tinggi cerobong yaitu $20 \mathrm{~cm}, 50 \mathrm{~cm}, 80 \mathrm{~cm}, 110 \mathrm{~cm}$ dan $140 \mathrm{~cm}$ dengan ketebalan gabah yaitu $7 \mathrm{~cm}, 5 \mathrm{~cm}$, dan $3 \mathrm{~cm}$. Data-data yang diperoleh kemudian dianalisis untuk mendapatkan efisiensi dari alat pengering. Hasil penelitian menunjukan bahwa waktu yang diperlukan untuk menurunkan kadar air gabah panen dari $24,6 \%$ menjadi kadar air giling 13,6\% - 13,85\% adalah 4 jam - 6,5 jam dengan efisiensi 34,323 \% untuk tebal gabah $7 \mathrm{~cm}, 31,480 \%$ tebal gabah $5 \mathrm{~cm}$ dan 30,122 tebal gabah $3 \mathrm{~cm}$ pada ketinggian cerobong $80 \mathrm{~cm}$.
\end{abstract}

\begin{abstract}
Analysis of Changes in Drying Time against High Chimney Variations. This study aims to find out the efficiency of grain dryers using a chimney and a fan as suction air from the collector into the drying chamber.The research was conducted at the Central of Laboratory Department of Mechanical Engineering Faculty of Engineering, University of Muslim Indonesia, Makassar. A dryer was made from a zinc plate of $0.2 \mathrm{~mm}$ as collector by using a hot-air and solar energy as a drying medium. It was expected that this tool can dry grain quickly with evenly distributed drying level or water content. There were five variations of the Chimney : $20 \mathrm{~cm}, 50 \mathrm{~cm}, 80 \mathrm{~cm}, 110 \mathrm{~cm}$ and $140 \mathrm{~cm}$ with the grain thickness of $7 \mathrm{~cm}, 5$ $\mathrm{cm}$ and $3 \mathrm{~cm}$. The data were then analyzed to obtained the efficiency of the dryer. The results reveal that the time required to lower the water content of the harvest grain from $24.6 \%$ to $13.6 \%-13.85 \%$ of milled moisture was 4 hours - 6.5 hours with an efficiency of $34,232 \%$ for grain thicknes $7 \mathrm{~cm}, 31,480 \%$ for grain thicknes $5 \mathrm{~cm}$ and 30,122 for grain thicknes $3 \mathrm{~cm}$ at $80 \mathrm{~cm}$ chimney height.
\end{abstract}

Kata Kunci : Efisiensi, gabah, kadar air, kolektor, pengeringan, variasi cerobong

\section{Pendahuluan}

Kemajuan teknologi pascapanen di Indonesia menuntut tersedianya bahan baku yang bermutu tinggi untuk industri pengolahan hasil pertanian. Produk-produk pertanian yang berbentuk butiran, seperti : jagung, padi, kacang-kacangan, kopi, dan lain-lain memerlukan perhatian yang lebih serius, terutama pada proses pengawetan. Proses pengeringan memegang peranan penting dalam pengawetan suatu bahan. Proses pengeringan juga membantu mempermudah penyimpanan produk pertanian dalam rangka pendistribusian baik dalam skala domestik maupun ekspor. Proses pengeringan butiran bertujuan untuk mengurangi kandungan airnya sampai batas-batas tertentu, agar tidak terjadi kerusakan akibat aktivitas metabolisme oleh mikro organisme [1].

Proses pengeringan hasil-hasil pertanian khususnya gabah yang dilakukan oleh para petani di Indonesia, umumnya masih memanfaatkan tenaga matahari sebagai tenaga pengeringnya dimana pengeringan masih dilakukan dengan cara yang relatif sederhana, yaitu dengan dipanaskan pada terik matahari atau dijemur. Hal ini kurang efisien karena memerlukan waktu berhari-hari dan tempat yang luas. Oleh sebab itu dengan 
pertumbuhan teknologi pada jaman sekarang ini yang didominasi alat yang serba modern dan proses pengoperasiannya yang sedemikian teraturnya diperlukan mesin yang menunjang proses pengeringan gabah untuk dapat meningkatkan kualitas dari makanan pokok di Indonesia tersebut, karena dengan pengeringan yang baik gabah menjadi tidak cepat rusak dan kandungan mineralnya tetap terjaga. Bila gabah tersebut tidak berhasil dikeringkan sampai kandungan air tertentu, maka gabah tersebut akan berkecambah atau bahkan membusuk karena aktivitas metabolisme oleh mikroorganisme. Tentu saja, hal ini akan mengurangi mutu dari gabah tersebut.

Sebagai salah satu alternatif pemecahan masalah tersebut, maka perlu dilakukan kajian untuk membuat suatu alat pengering yang dapat membantu para petani dalam mengeringkan hasil pertanian, khususnya gabah. Alat pengering yang akan dikaji karakteristik pengeringannya adalah alat pengering kabinet (tray dryer) yang menggunakan udara panas dengan tenaga matahari sebagai media pengering. Udara panas dalam ruang pengering akan menyerap kadar air gabah kemudian dikeluarkan melalui cerobong udara. Alat tersebut, diharapkan dapat mengeringkan hasil gabah dengan tingkat kekeringan (kandungan air) pada bahan yang merata. Selain itu, penggunaan alat pengering tersebut juga diharapkan dapat memaksimalkan energi dari sinar matahari dimana energi matahari ini merupakan salah satu energi terbaharukan [2].

Merancang dan membuat alat pengering gabah dengan kolektor sekunder sesudah alat pengering dengan seng plat gabah $0,2 \mathrm{~mm}$ sebagai penyerap dengan menggunakan tenaga matahari untuk memanaskan udara sebagai media pengering. Hasil penelitian menunjukan bahwa waktu yang diperlukan untuk menurunkan kadar air gabah panen dari $24,75 \%$ menjadi kadar air gabah kering giling $13.43 \%-13.82 \%$ adalah 3 jam -5.5 jam dengan efisiensi $9.88 \%$ - $44.96 \%$ untuk alat yang menggunakan kolektor sekunder dan 4 jam - 6.5 jam dengan efisiensi $8.65 \%$ - $33.72 \%$ pada alat tanpa menggunakan kolektor sekunder [3].

Dengan penemuan alat pengering gabah, dalam ilmu pengetahuan dan teknologi dapat memberikan andil yang cukup berarti bagi perkembangan dunia usaha dan industri. Manfaat lain yang dapat diperoleh petani adalah kerusakan gabah karena proses pengeringan yang tidak sempurna dapat dikurangi, dan petani dapat menikmati harga gabah/beras yang lebih baik.

\section{Landasan Teori}

\subsection{Teori Pengeringan}

Bahasa ilmiah pengeringan adalah penghidratan, yang berarti menghilangkan air dari suatu bahan. Proses pengeringan atau penghidratan berlaku apabila bahan yang dikeringkan kehilangan sebahagian atau keseluruhan air yang dikandungnya. Proses utama yang terjadi pada proses pengeringan adalah penguapan. Penguapan terjadi apabila air yang dikandung oleh suatu bahan menguap, yaitu apabila panas diberikan kepada bahan tersebut. Panas ini dapat diberikan melalui berbagai sumber, seperti kayu api, minyak dan gas, arang, batu bara ataupun tenaga surya.

Pengeringan juga dapat berlangsung dengan cara lain yaitu dengan memecahkan ikatan molekul-molekul air yang terdapat di dalam bahan. Apabila ikatan molekul-molekul air yang terdiri dari unsur dasar oksigen dan hidrogen dipecahkan, maka molekul tersebut akan keluar dari bahan. Akibatnya bahan tersebut akan kehilangan air yang dikandungnya.

Cara ini juga disebut pengeringan atau penghidratan. Untuk memecahkan ikatan oksigen dan hidrogen ini, bisaanya digunakan gelombang mikro. Gelombang mikro merambat dengan frekuensi yang tinggi. Apabila gelombang mikro disesuaikan setara dengan getaran molekulmolekul air maka akan terjadi resonansi yaitu ikatan molekul-molekul oksigen dan hidrogen digetarkan dengan kuat pada frekuensi gelombang mikro yang diberikan sehingga ikatannya pecah.

Dalam sektor pertanian sistem pengeringan yang umum digunakan adalah tenaga surya. Pada sistem tenaga surya ini, bahan diexpose ke sinar surya secara langsung maupun tidak langsung. Uap air yang terjadi dipindahkan dari tempat pengeringan melalui aliran udara. Proses aliran udara ini terjadi karena terdapat perbedaan 
tekanan. Perbedaan tekanan udara ini dapat terjadi secara konveksi bebas maupun konveksi paksa. Konveksi bebas terjadi tanpa bantuan luar, yaitu pengaliran udara hanya bergantung pada perbedaan tekanan yang disebabkan oleh perbedaan densitas udara, sedangkan pada konveksi secara paksa digunakan kipas untuk memaksa gerakan udara.

Pada sistem pengeringan yang bersumberkan tenaga minyak, bahan yang akan dikeringkan diletakkan di dalam suatu ketel tertutup. Udara panas hasil pembakaran minyak dialirkan mengenai permukaan bahan tersebut. Akhir-akhir ini, cara tersebut di atas juga digunakan dalam teknologi tenaga surya. Udara yang dipanaskan oleh pengumpul surya digunakan untuk menguapkan air pada bahan.

Udara merupakan medium yang sangat penting dalam proses pengeringan, untuk menghantar panas kepada bahan yang hendak dikeringkan, karena udara satu-satunya medium yang sangat mudah diperoleh dan tidak memerlukan biaya operasional.

\subsection{Pengeringan Gabah}

Pengeringan Gabah adalah proses menurunkan kadar air gabah dari kadar air panen 22\%-26\% menjadi gabah kering giling kadar air $12 \%-14 \%$ dengan bantuan alat pengering [4].

Gabah memiliki 2 (dua) komponen utama yaitu air dan bahan kering. Banyaknya air yang dikandung dalam gabah disebut kadar air dan dinyatakan dengan persen $(\%)$. Pengeringan dilakukan karena kadar air gabah panen umumnya masih tinggi yaitu $22 \%$ - 26\% tergantung cuaca pada saat pemanenan. Pengeringan gabah adalah suatu perlakuan yang bertujuan menurunkan kadar air sehingga gabah dapat disimpan lama, daya kecambah dapat dipertahankan, mutu gabah dapat dijaga tetap baik (tidak kering, tidak berkecambah dan tidak berjamur), memudahkan proses penggilingan dan untuk meningkatkan randemen serta menghasilkan beras gilingan yang baik [5].

Pengeringan harus sesegera mungkin dimulai sejak saat dipanen. Apabila pengeringan tidak dapat dilangsungkan, maka usahakan agar gabah yang masih basah tidak ditumpuk tetapi ditebarkan untuk menghidarkan dari kemungkinan terjadinya proses fermentasi. Pengeringan akan semakin cepat apabila ada pemanasan, perluasan permukaan gabah padi dan aliran udara. Adapun tujuan pengeringan disamping untuk menekan biaya transportasi juga untuk menurunkan kadar air dari 22-26\% menjadi 14\%, agar dapat disimpan lebih lama serta menghasilkan beras yang berkualitas baik. Proses pengeringan gabah sebaiknya dilakukan secara merata, perlahanlahan dengan suhu yang tidak terlalu tinggi. Pengeringan yang kurang merata, akan menyebabkan timbulnya retak-retak pada gabah dan sebaliknya gabah yang terlalu kering akan mudah pecah tatkala digiling. Sedangkan dalam kondisi yang masih terlalu basah disamping sulit untuk digiling juga kurang baik ditinjau dan segi penyimpanannya karena akan gampang terserang hama gudang, cendawan dan jamur.

Alat pengering gabah merupakan suatu sistem yang terdiri dari beberapa komponen alat yang dapat mengeringkan gabah hasil panen tanpa menjemur secara langsung di bawah sinar matahari. Alat pengering tersebut mempunyai beberapa keuntungan diantaranya terjamin kebersihan dan kualitas bahan yang dikeringkan.

\subsection{Metode Pengeringan}

\subsubsection{Pengeringan alami}

Pengeringan alami dengan menjemur atau mengangin-anginkan, yang dilakukan antara lain dengan cara pengeringan di atas lantai (lamporan), pengeringan di atas rak, pengeringan dengan ikatan-ikatan ditumpuk, pengeringan dengan ikatan-ikatan yang diberdirikan dan pengeringan dengan memakai tonggak.

Penjemuran gabah pada lantai jemur (lamporan) adalah cara pengeringan gabah secara alami yang praktis, murah, sederhana dan umum digunakan oleh para petani. Energi untuk penguapan diperoleh dari angin dan sinar matahari. Lamporan harus bersih agar gabah padi yang dikeringkan tidak kotor. Lamporan haruslah memenuhi berbagai syarat antara lain tidak menimbulkan panas yang terlalu tinggi, mudah dibersihkan dan dikeringkan, tidak basah sewaktu digunakan, dan tidak berlubang-lubang. Lamporan pada umumnya dibuat dari semen, 
permukaannya agak miring dan bergelombang dengan maksud agar air tidak menggenang, mudah dikeringkan dan permukaannya menjadi lebih luas. Cara penjemuran gabah dihamparkan di lamporan setipis mungkin, namun untuk efisiensi dan mengurangi pengaruh lantai semen yang terlalu panas maka tebal lapisan dianjurkan sekitar $5-7 \mathrm{~cm}$. Padi harus sering dibolak-balik secara merata minimal 2 jam sekali. Pengeringan padi dapat dilakukan selama $\pm 1-3$ hari tergantung dari cuaca (mendung atau terik matahari). Penjemuran sebaiknya dilakukan di tempat yang bebas menerima sinar matahari, bebas banjir dan bebas dari gangguan unggas dan binatang pengganggu lainnya, penjemuran sebaiknya dilakukan dari pukul 07.00 - 16.00 atau tergantung pada intensitas panas sinar matahari.

\subsubsection{Pengeringan Buatan}

Pengeringan buatan mempunyai kelebihan dibanding pengeringan alami yaitu waktu penjemuran yang lebih singkat dan gabah yang dijemur lebih bersih dan terlindung dari debu, hujan dan lain-lain. Pengering buatan bermacammacam, ada yang menggunakan listrik, matahari, bahan bakar sekam dan lain-lain.

Pengeringan buatan dapat menggunakan udara dipanaskan. Udara yang dipanaskan tersebut dialirkan ke bahan yang akan dikeringkan dengan menggunakan alat penghembus fan. Pengeringan dengan menggunakan alat mekanis (pengeringan buatan) yang menggunakan tambahan panas memberikan beberapa keuntungan diantaranya tidak tergantung cuaca, kapasitas pengeringan dapat dipilih sesuai dengan yang diperlukan, tidak memerlukan tempat yang luas, serta kondisi pengeringan dapat dikontrol.

Pengeringan mekanis ini memerlukan energi untuk memanaskan alat pengering, mengimbangi radiasi panas yang keluar dari alat, memanaskan bahan, menguapkan air bahan serta menggerakkan udara. Alat pengering buatan pada umumnya terdiri dari tenaga penggerak dan kipas, unit pemanas (heater) serta alat-alat kontrol. Sebagai sumber tenaga untuk mengalirkan udara penggerak dapat digunakan motor bakar atau motor listrik. Untuk alat pengering dengan unit pemanas, beberapa macam sumber energi panas yang bisaanya dipakai adalah gas, minyak bumi, batubara atau elemen pemanas listrik.

\subsubsection{Penentuan Kadar Air Gabah}

Kandungan air suatu bahan dapat dinyatakan dalam wet basis (basis basah) atau dry basis (basis kering). Kandungan kelembaban dalam wet basis menyatakan perbandingan massa air dalam bahan dengan massa total bahan. Persentase kadar air $M$ dari sampel bahan berdasarkan basis basah sesuai dengan persamaan [4]:

$$
M=\left(\frac{w-d}{w}\right) 100 \%
$$

Untuk w adalah massa sampel basah (kg) dan d adalah massa sampel kering (kg). Dalam pengujian ini, prosentase kadar air ditentukan dengan menggunakan alat pengetes kadar air.

\subsubsection{Udara dan Uap Air}

Jumlah uap air dalam udara ditentukan oleh tekanan uap airnya, sedangkan tekanan uap air jenuh bergantung pada temperatur dan tidak bergantung pada jumlah udara di dalam ruangan. Perbandingan antara tekanan uap air di dalam udara $p_{\mathrm{v}}$ dan tekanan uap air jenuh $\mathrm{p}_{\mathrm{s}}$ pada temperatur yang sama disebut kelembaban relatif $\varnothing$ yang dinyatakan dalam relasi [6]:

$$
\phi=\left(\frac{p_{v}}{p_{s}}\right)(\%)
$$

Kelembaban absolut (rasio kelembaban) $\omega$ udara yang mengandung uap air adalah perbandingan antara massa uap air $m_{v}$ dan massa udara kering $\mathrm{m}_{\mathrm{d}}$ dalam volume yang sama [6] :

$$
\begin{aligned}
\omega & =\frac{m_{w}}{m_{d}} \\
& =0.622 \phi \frac{p_{s}}{p_{d}}(\mathrm{~kg} \text { air } / \mathrm{kg} \text { udara kering })
\end{aligned}
$$

\subsubsection{Massa Udara Kering}

Laju aliran massa untuk pengeringan dilakukan dengan menggunakan alat pitot, Gambar 1, guna menentukan kecepatan udara [6]. 
Kecepatan udara adalah

$$
V=\sqrt{\frac{2 \times \Delta p n}{\rho u d}}(\mathrm{~m} / \mathrm{s})
$$

Sehingga laju aliran massa udara adalah [6] :

$$
m_{a}=\rho_{a} \times A \times V(\mathrm{~kg} / \mathrm{s})
$$

Dengan A adalah luas penampang cerobong udara $\left(\mathrm{m}^{2}\right)$.

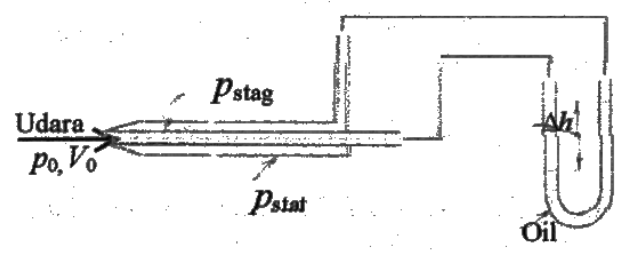

Gambar 1. Alat pitot

\subsubsection{Kesetimbangan Energi dalam Proses Pengeringan}

Proses pengeringan adalah penguapan uap air dari gabah yang dilakukan oleh udara bertemperatur lebih tinggi dan memiliki kelembaban relatif rendah.

Kesetimbangan energi dalam pengeringan adalah [6] :

$$
m_{w} L=m_{a} C_{p}\left(T_{i}-T_{f}\right)(k J)
$$

Untuk $\mathrm{m}_{\mathrm{w}}$ adalah massa air yang diuapkan $(\mathrm{kg}), \mathrm{m}_{\mathrm{a}}$ adalah massa udara pengering $(\mathrm{kg}), \mathrm{L}$ adalah panas laten penguapan air $(\mathrm{kJ} / \mathrm{kg}), \mathrm{T}_{\mathrm{i}}$ adalah temperatur awal udara pengering $\left({ }^{\circ} \mathrm{C}\right)$, dan $\mathrm{T}_{\mathrm{f}}$ adalah temperatur akhir udara pengering $\left({ }^{\circ} \mathrm{C}\right)$.

Jumlah massa air yang diuapkan $\mathrm{m}_{\mathrm{w}}$ yang dihitung berdasarkan kadar air awal $\mathrm{M}_{\mathrm{i}}$ dan kadar air akhir $\mathbf{M}_{\mathrm{f}}$ dalam gabah dapat dinyatakan dalam relasi berikut [6]:

$$
m_{w}=w_{i}\left(M_{i}-M_{f}\right) /\left(100-M_{f}\right)(k g)
$$

\subsubsection{Proses Pengeringan}

Bila udara yang mengandung uap air dipanaskan tanpa penambahan atau pengurangan air, maka kelembaban absolutnya tetap, dan kelembaban relatifnya berkurang [4].

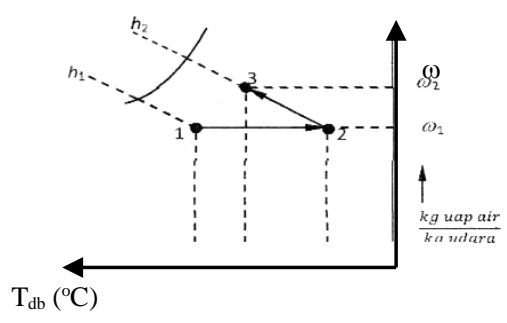

Gambar 2. Diagram pada peta psikrometrik Proses pemanasan (1-2) dan proses pengeringan (2-3)

Selama proses pengeringan, temperatur bola kering berkurang sedangkan kelembaban absolut dan kelembaban relatif bertambah, temperatur bola basah dan entalpi tetap, seperti terlihat pada diagram psikrometrik di atas (Gambar 2). Dari diagram psikrometrik juga bisa didapatkan jumlah massa air yang diuapkan dan dapat dihitung dengan persamaan berikut [7] :

$$
m_{w}=w_{a}\left(\omega_{2}-\omega_{1}\right)(k g)
$$

Untuk $\mathrm{m}_{\mathrm{a}}$ adalah massa udara pengering $(\mathrm{kg})$, $\omega_{1}$ adalah rasio kelembaban pada awal pengeringan ( $\mathrm{kg}$ air/kg udara kering), dan $\omega_{2}$ adalah rasio kelembaban setelah pengeringan $(\mathrm{kg}$ air/kg udara kering).

\subsubsection{Efisiensi Sistem Pengering}

Efisiensi sistem pengeringan matahari dapat dievaluasi berdasarkan kinerja termal atau tingkat pengeringan produk. Efisiensi termal dari pengering tenaga surya dapat didefinisikan sebagai energi termal digunakan untuk pengeringan dibagi dengan energi termal yang tersedia untuk pengeringan [8].

$$
\eta_{t h}=\frac{m_{w} h_{f g}}{m_{a} C_{p a}\left(\left(T_{i}-T_{a}\right)+\left(T_{i}-T_{f}\right)\right)}
$$

Jika $\mathrm{P}_{\mathrm{p}}$ adalah daya yang diperlukan untuk menguapkan air dari gabah, maka :

$$
p_{p}=m_{w} h_{f g}(W)
$$

Untuk $\mathrm{P}_{\mathrm{t}}$ adalah daya total, dapat dituliskan sebagai berikut :

$$
p_{t}=m_{a} C_{p a}\left\{\left(T_{i}-T_{a}\right)+\left(T_{i}-T_{f}\right)\right\}
$$


Sedangkan $\dot{\mathrm{m}}_{\mathrm{w}}$ adalah laju aliran massa air yang diuapkan $(\mathrm{kg} / \mathrm{s}), \dot{\mathrm{m}}_{\mathrm{a}}$ adalah laju aliran massa udara pengering $(\mathrm{kg} / \mathrm{s}), \mathrm{C}_{\mathrm{pa}}$ adalah panas spesifik udara pengering $(\mathrm{J} / \mathrm{kg} . \mathrm{K}), \mathrm{T}_{\mathrm{i}}$ adalah temperatur udara masuk ruang pengering $(\mathrm{K}), \mathrm{T}_{\mathrm{f}}$ adalah temperatur udara meninggalkan ruang pengering/cerobong $(\mathrm{K}), \mathrm{T}_{\mathrm{a}}$ adalah temperatur udara luar $(\mathrm{K})$ dan $\mathrm{h}_{\mathrm{fg}}$ adalah kalor laten untuk penguapan $(\mathrm{J} / \mathrm{kg})$.

Efisiensi juga dapat dihitung dari perbandingan energi yang masuk dengan energi berguna untuk pengeringan [9]:

$$
\eta_{t h}=\frac{P_{p}}{Q_{c}}
$$

Jika Qc adalah kalor yang diterima oleh kolektor (W), maka :

$$
Q_{c}=I_{g} \times A_{c}
$$

\section{Metodologi Penelitian}

Penelitian ini dilaksanakan di Laboratorium Teknik Mesin Jurusan Teknik Mesin Fakultas Teknik Universitas Muslim Indonesia yang di mulai dari bulan Mei-Desember 2017 dengan merancang dan membuat alat pengering gabah dengan seng plat 0,2 mm sebagai kolektor dan menyiapkan peralatan pendukung berupa termokopel, testes kadar air (grain moisture meter), timbangan, pyranometer dan alat-alat lain untuk keperluan penelitian dengan variasi tinggi cerobong $20 \mathrm{~cm}, 50 \mathrm{~cm}, 80 \mathrm{~cm}, 110 \mathrm{~cm}$ dan 140 $\mathrm{cm}$. Dan keseluruhan data menyangkut berat dan kadar air gabah, temperatur, laju aliran massa udara dan waktu pengering pengeringan serta intensitas cahaya matahari yang di tampilkan pada penelitian ini bersumber dari penelitian yang dilakukan pada laboratorium.

Adapun langkah-langkah pengambilan data yang dilakukan secara eksperimental adalah :

- Memasang dan meletakkan alat pengering gabah di bawah sinar matahari.

- Memasang alat ukur berupa termokopel, tabung pitot dan pyranometer.

- Alat pengering dibiarkan beberapa saat sampai diperoleh panas yang stabil pada kolektor sebelum proses pengeringan dan pengukuran dilakukan.
- Menimbang dan mengukur ketebalan gabah sebelum dimasukkan ke ruang pengering dengan menggunakan timbangan dan mistar ukur.

- Mengukur besarnya Intensitas radiasi global matahari dengan mengunakan pyranometer.

- Mengukur temperatur udara sebelum masuk kolektor (temperatur sekeliling), temperatur udara meninggalkan kolektor masuk ruang pengering serta temperatur keluar ruang pengering yaitu mulai titik 1 sampai dengan titik 16 dengan menggunakan termokopel.

- Mengukur kadar air gabah dengan menggunakan tester/grain moisture meter.

- Pengukuran pada point 5-7 di atas dilakukan setiap 30 menit sampai diperoleh kadar air gabah kering giling antara $12 \%-14 \%$.

- Gabah yang telah kering dikeluarkan dari rak pengering kemudian ditimbang.

- Ulangi prosedur point $4-9$ di atas untuk variasi tinggi cerobong $20 \mathrm{~cm}, 50 \mathrm{~cm}, 80 \mathrm{~cm}$, $110 \mathrm{~cm}$ dan $140 \mathrm{~cm}$ dengan ketebalan gabah 3 $\mathrm{cm}, 5 \mathrm{~cm}$ dan $7 \mathrm{~cm}$

- Data-data hasil pengukuran ditulis dalam tabel data pengamatan kemudian dihitung dan dibuat dalam bentuk tabel dan grafik hasil penelitian untuk laju pengeringan yang terjadi dan efisiensi alat pengering selama proses pengeringan.

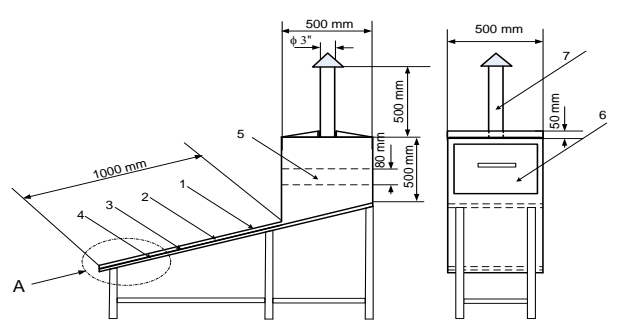

Gambar 3 . Alat pengering gabah

\section{Hasil dan analisis}

Setelah dilakukan analisis data melalui perhitungan pada data hasil penelitian, maka dapat dilihat pengaruh perubahan kadar air gabah sehubungan waktu pengeringan dan laju aliran massa udara pengering. Pada penelitian ini pengujian atau proses pengeringan dimulai pada pukul 08.00 Wita. 
4.1. Pengaruh Waktu Pengeringan terhadap Presentase Kadar Air Gabah

Pengaruh waktu pengeringan adalah berbanding terbalik dengan prosentase kadar air dari gabah.

Hal ini dapat dilihat pada Gambar 3. grafik hubungan antara prosentase kadar air (M) dengan waktu pengeringan (t) dimana semakin besar waktu yang digunakan dalam pengeringan maka prosentase kadar air dari gabah semakin kecil baik untuk ketebalan $7 \mathrm{~cm}, 5 \mathrm{~cm}$ maupun $3 \mathrm{~cm}$ dengan ketinggian cerobong $20 \mathrm{~cm}, 50 \mathrm{~cm}, 80 \mathrm{~cm}, 110$ $\mathrm{cm}$ dan $140 \mathrm{~cm}$.

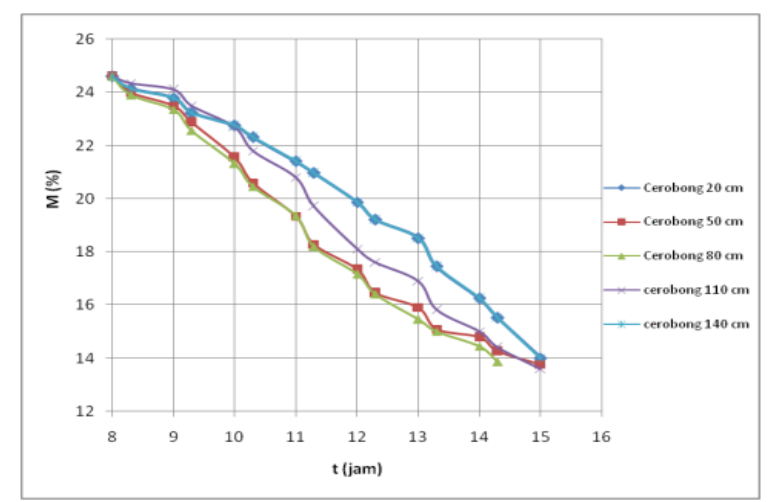

Gambar 4. Grafik hubungan antara kadar air gabah (M) dengan waktu pengeringan (t)

Hal ini disebabkan karena adanya penguapan yang terjadi pada gabah. Pada saat $\mathrm{t}=0$ (jam 08.30), gabah belum mengalami proses pengeringan, dimana kadar air gabah masih tinggi (24,6\%). Pengeringan gabah bertujuan untuk menurunkan kadar air gabah dari 24,6 \% menjadi $12-14 \%$ (Standar Bulog). Dari grafik terlihat bahwa semakin lama waktu yang digunakan maka proses pengeringan akan semakin lama pula, dimana semakin lama proses pengeringan maka prosentase kadar air dari gabah akan semakin kecil karena semakin banyak uap air yang menguap dari gabah akibat adanya aliran udara panas yang dilewatkan pada gabah. Proses pengeringan sangat dipengaruhi oleh tinggi cerobong yang digunakan hal ini disebabkan aliran udara panas yang keluar melalui cerobong membawa upa air pada gabah yang dikeringkan. Dimana pada ketinggian cerobong 80 kemampuan udara pengering mengambil air dalam gabah sangat sehingga laju pengeringan semakin cepat sehingga waktu yang dibutuhkan untuk mengeringkan gabah semakin kecil.

Tabel 1. Tabel kadar air gabah sebelum dan sesudah pengeringan

\begin{tabular}{|c|c|c|c|c|}
\hline \multirow{2}{*}{$\begin{array}{l}\text { Tinggi } \\
\text { cerobong } \\
(\mathbf{c m})\end{array}$} & \multirow{2}{*}{$\begin{array}{c}\text { Kadar air } \\
\text { awal, } \mathbf{M}_{\mathbf{i}} \\
(\%)\end{array}$} & \multicolumn{3}{|c|}{ Kadar air akhir, $M_{f}(\%)$} \\
\hline & & $7 \mathrm{~cm}$ & n & $3 \mathrm{~cm}$ \\
\hline 20 & 24,60 & 14,00 & 1392 & 1400 \\
\hline 50 & 24,60 & & 13,80 & \\
\hline 80 & 4,60 & 13,85 & 14,00 & 14,00 \\
\hline 110 & 24,60 & 13,60 & 13,72 & 13,89 \\
\hline 140 & 24,60 & 13.83 & 13,80 & 13,92 \\
\hline
\end{tabular}

Dari Gambar 4 grafik juga terlihat bahwa waktu pengeringan $(\mathrm{t})$ berbanding lurus dengan ketebalan gabah (h), dimana semakin tebal gabah yang mau dikeringkan semakin lama pula waktu yang digunakan untuk mengeringkan gabah sampai kadar air giling $12-14 \%$. Hal ini disebabkan karena gabah yang tebal mengandung lebih banyak uap air dibandingkan dengan gabah yang ketebalannya lebih kecil sehingga dibutuhkan waktu lebih banyak untuk mengeringkan gabah yang mempunyai ketebalan yang lebih besar.

Tabel 2. Tabel waktu yang diperlukan untuk pengeringan gabah

\begin{tabular}{cccc}
\hline \multirow{2}{*}{$\begin{array}{c}\text { Tinggi } \\
\text { cerobong } \\
(\mathbf{c m})\end{array}$} & \multicolumn{3}{c}{ Waktu Pengering (jam) } \\
\cline { 2 - 4 } & $\mathbf{7} \mathbf{~ c m}$ & $\mathbf{5} \mathbf{~ c m}$ & $\mathbf{3} \mathbf{~ c m}$ \\
\hline 20 & 7 & 6 & 4,5 \\
\hline 50 & 7 & 6 & 4,5 \\
\hline 80 & 6,5 & 5,5 & 4 \\
\hline 110 & 7 & 6 & 4,5 \\
\hline 140 & 7 & 6 & 4,5 \\
\hline
\end{tabular}

\subsection{Efisiensi Alat Pengering}

Efisiensi alat pengering akan naik sampai mencapai nilai maksimun kemudian turun kembali seiring dengan bertambahnya waktu pengeringan dari gabah seperti terlihat pada grafik hubungan antara efisiensi alat pengering dengan waktu pengeringan di bawah ini 


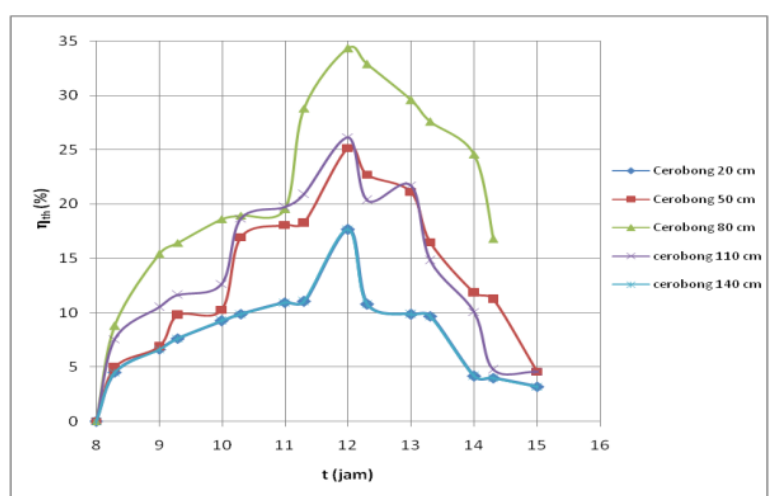

Gambar 5. Grafik hubungan antara efisiensi $\left(\eta_{\text {th }}\right)$ dengan waktu pengeringan $(t)$ untuk ketebalan gabah 7 cm

Efisiensi terbaik pada pengujian untuk tebal gabah $7 \mathrm{~cm}$ yang menggunakan cerobong dengan ketinggian $80 \mathrm{~cm}$ dicapai setelah pengeringan berlangsung selama 6,5 jam dan untuk tebal gabah $5 \mathrm{~cm}$ setelah 5,5 jam pada cerobong dengan tinggi $80 \mathrm{~cm}$ sedangkan tebal $3 \mathrm{~cm}$ setelah 4 jam, hal ini disebabkan pada ketinggian cerobong tersebut dan pada jam ini energi atau panas yang dibawah oleh udara pengering dapat dimanfaatkan secara maksimal untuk menguapkan air dari gabah dan pada jam ini alat pengering gabah bekerja secara optimum.

Tabel 3. Tabel efisiensi rata-rata dari alat pengering gabah

\begin{tabular}{cccc}
\hline Tinggi & \multicolumn{3}{c}{ Efisiensi (\%) } \\
\cline { 2 - 4 } cerobong $(\mathrm{cm})$ & $7 \mathrm{~cm}$ & $5 \mathrm{~cm}$ & $3 \mathrm{~cm}$ \\
\hline 20 & 7,947 & 8,148 & 10,547 \\
\hline 50 & 13,213 & 9,740 & 11,286 \\
\hline 80 & 20,87 & 15,64 & 14,17 \\
\hline 110 & 13,597 & 13,209 & 12,446 \\
\hline 140 & 7,090 & 9,832 & 5,614 \\
\hline
\end{tabular}

\section{Kesimpulan}

Persentase kadar air gabah yang dikeringkan berbanding terbalik dengan waktu pengering baik untuk alat pengering yang menggunakan cerobong dengan variasi ketinggian. Kadar air sebelum dikeringkan sebesar 24,60\% dan sesudah dikeringkan berkisar antara $13,6 \%$ sampai dengan $13,85 \%$ dengan waktu pengering yang diperlukan untuk mencapai persentase kadar air giling gabah $4-6,5$ jam. Efisiensi alat pengering gabah akan meningkat seiring dengan bertambahnya tebal gabah dimana efisiensi maksimum diperoleh pada ketebalan gabah $7 \mathrm{~cm}$ dengan ketinggian cerobong $80 \mathrm{~cm}$ yaitu sebesar 34,323\%. Efisiensi pada alat pengering gabah dengan menggunakan cerobong dengan tinggi $80 \mathrm{~cm}$ lebih baik dibandingkan dengan efisiensi pada ketinggian cerobong yang lain.

\section{Referensi}

[1] Mohsenin, 1980. Physical Properties of Plant and Animal materials. 2nd edition. Gordon and Breach Science. New York USA.

[2] Selyus Rantepulung 2012. Analisis Efisiensi Pengering Gabah dengan Tenaga Surya. Unhas Makassar.

[3] Suanggana Doddy, 2014,. Analisa waktu Pengeringan Antara 2 Plat Pengering Gabah Dengan Dan Tanpa Menggunakan Kolektor Sekunder. Unhas Makassar.

[4] Duffie, A. John, Beckman, A. William, 1980. Solar Engineering Of Thermal Processes. Wiley and Sons, New York, USA.

[5] Dirk E. Maier, Fred W. Bakker-Arkema, 2002. Grain Drying Systems. St. Charles, Illinois, U.S.A.

[6] Himran Syukri, 2005. Energi Surya. CV.Bintang Lamumpatue, Makassar.

[7] Himran Syukri, 2011. Kajian Pada Alat Pengering Gabah Dengan Tungku Sekam Sebagai Pemanas Udara Pengering. Mekanika, Jurnal Teknik Mesin dan Industri, Makassar.

[8] Holman J.P, 1988, Perpindahan Kalor, $6^{\text {th }}$ Ed, Erlangga, Jakarta.

[9] Jansen, J. Ted, Arismunandar, W, 1995. Teknologi Rekayasa Surya. PT. Pradnya Paramita, Jakarta. 